$\xi=-1$

\title{
Optimizing Milk Run and Use of Bin-Packing in Waste Collection Problems
}

\author{
S. $\operatorname{Prasad}^{1}$, J. V. Kureethara ${ }^{1} *$ \\ ${ }^{l}$ CHRIST (Deemed to be University, Hosur Road, Bangalore, Karnataka, India - 560029 \\ *Corresponding author E-mail: frjoseph@ christuniversity.in
}

\begin{abstract}
This paper uses the concepts of milk runs as well as bin packing in order to optimize collection and reduce cost. Using the concept of "milk run" and an approach of time minimization, we can optimize the number of trucks and other vehicles used for picking and transporting waste. The objective function involves cost of transportation and is linked to distance travelled to dispose wastes. The constraints are those of vehicle capacity. The profile of different types of trucks obtained from milk run is used to compute number of trucks as well as to allot them to different trips.
\end{abstract}

Keywords: Milk run, Bin packing, Waste management, Time minimization

\section{Introduction}

The term milk run is originated from dairy industry wherein a single tanker collects milk every day and transports it to a milk processing firm, after collecting from various dairy farmers. In place of several suppliers transporting in separate vehicles, one vehicle can be routed for the same purpose. It is an optimization method with respect to cost and time, which helps in planning and scheduling in a transportation problem. It can be formulated keeping in mind the variables, which are significant to a study. In case of waste from households, pick-up routing is very important and has to be planned in a systematic manner. If it is collected in a random unplanned way, it not only leads to excess expenditure but also losses, as some wastes have to reach compost plants and recycling units as soon as possible.

Milk run is suitable for optimizing trucking as there is demand at multiple locations for pickup of waste and there are a number of vehicles involved in this transportation, which needs to be optimized. Using milk run, there would be cost minimization, reduced pick-up / delivery time and more efficient service as seen by the application of the concept. In the model proposed, costs of transportation are considered to find the number of trips of small/large trucks.

\section{Literature Review}

After the World War II, car manufacturers in Japan were in a stiff competition as the market was small and diverse car types had to be produced [10]. This situation drove Toyota engineers to systematize their transports between and within their plants "at fixed times along fixed routes" [1]. This concept was referred to as "milk run" and helps in transporting lesser amounts of a sizeable number of different items without increasing cost of transport.

According to Chopra and Meindl [4], Milk Run is very useful to transport material from suppliers to the plant. Many researchers like Brar et al.[2], Sadjadi et al. [8] have worked on minimizing the cost of the Milk Run. They formulated a mixed integer problem by minimizing cost of transportation as well as inventory costs at the same time. Du et al. [5] consider dynamic solution that is how to optimize dispatch of vehicles real time for enhanced performance of the system. Milk run logistics was also implemented for jaguar land rover by DHL (Dalsey, Hillblom and Lynn), which is a company from Germany andtheir model improved efficiency and reduced cost [6]. Chen and Shuaiying [3] constructed a model whose objective was to optimize cost. They applied this concept to the hub of suppliers wherein multiple suppliers are present. The solution was an improved replenishment policy without considering the condition of penalty cost.

Vij and Bolia [9] formulated a milk run model for time minimization and used the result obtained to a bin-packing problem. Anne Meyer, in her thesis, discussed a model, which is based on cyclic inventory and periodic vehicle routing problem. In this model, there is a heterogeneous fleet with respect to capacity and cost [7].

\section{Model Description}

The BBMP decides the window timings to pick up waste from households and for unloading that into compactor truck stationed at certain locations. (These locations can be located using facility location model) On any given day, the amount of waste generated can be calculated and also, the capacity of various trucks is known in advance. We assume that trucks are available for 12 hours (6am to $6 \mathrm{pm}$ ), but can be allotted to a particular collection point for only a few hours (say 1.50-3 hrs.).

Objective function is about minimizing time of collection of waste while adhering to capacity constraints. The model is built in two stages.

- $\quad$ Stage I: To obtain the number of trips of small and large vehicles (Milk run).

- $\quad$ Stage II: To obtain the number of vehicles required and allotment of vehicles to trips (Bin packing). 


\section{Mathematical Model for Milk run}

Milk run is concerned with round trip times of vehicles. In this model, the term "trip" refers to a round trip, that is time for vehicle to start from depot (or the starting point in the area, in case of personnel), pick garbage, deposit in the transfer station/ large truck and return to depot.

1.Waste is transferred from collection points at various time periods and is taken to transfer station daily.

2.Compostable waste is sent to compost plant thrice a week from transfer stations.

3. Remaining waste is sent to either landfills or to recycling units, depending on their usefulness thrice a week. This reduces transportation cost as well as congestion on roads

4. Waste is compacted to nearly $181 \%$ of its weight so this point is considered to reduce the weight which exists from transfer station.

5.Capacity and transportation cost remains same in all time periods.

\subsection{Variables (Input parameters) used in the Model}

1. $\mathrm{A}_{\mathrm{i}}$ is the amount of waste collected at each collection point $i$

2. $X_{\mathrm{i}}$ is the number of trips of large trucks from $i$

3. $1_{\mathrm{i}}$ is the time taken by one large trip

4. $\mathrm{Y}_{\mathrm{i}}$ is the number of trips of small trucks from $i$

5. $\mathrm{s}_{\mathrm{i}}$ is the time taken by one small trip

6. $\mathrm{C}_{\mathrm{s}}$ is the capacity of small trucks

7. $C_{1}$ is the capacity of large trucks Title of the paper

The objective function is to minimize the time taken for each milk run. Thus we have:

Minimize $\mathrm{T}=\sum \mathrm{X}_{\mathrm{i}} \mathrm{l}_{\mathrm{i}}+\mathrm{Y}_{\mathrm{i}} \mathrm{s}_{\mathrm{i}}, i=1$ to $n$

subject to:

$\mathrm{C}_{\mathrm{i}} \mathrm{X}_{\mathrm{i}}+\mathrm{C}_{\mathrm{s}} \mathrm{Y}_{\mathrm{i}} \geq \mathrm{A}_{\mathrm{i}}$

The constraints are that of capacity of vehicles. The amount of waste carried from a particular collection point using either or both vehicles must be greater than or equal to the total amount of waste collected there.

\section{Application of the model to data}

Consider the following data for four collection points. To make the model simple, we consider only one sink $\mathrm{j}$ (compactor location). Collection point details in Jayanagar $7^{\text {th }}$ and $4^{\text {th }}$ Block, Bangalore, India.

Table 1: Details of collection points

\begin{tabular}{|c|c|}
\hline Collection point & Location \\
\hline A & 32 A cross road, $7^{\text {th }}$ block \\
\hline B & Jains prakruti apartments, K. R. Road \\
\hline C & $12^{\text {th }}$ Cross \\
\hline D & $8^{\text {th }}$ main, $4^{\text {th }}$ Block \\
\hline E & $22^{\text {nd }}$ cross road, $7^{\text {th }}$ block \\
\hline F & $19^{\text {th }}$ cross road, $4^{\text {th }}$ block \\
\hline
\end{tabular}

Table 2: Details of collection points

\begin{tabular}{|c|c|c|c|c|c|c|}
\hline Collection point $(i)$ & $\mathrm{A}$ & $\mathrm{B}$ & $\mathrm{C}$ & $\mathrm{D}$ & $\mathrm{E}$ & $\mathrm{F}$ \\
\hline Time $j$ (min) (Larger trucks) & 135 & 104 & 135 & 140 & 120 & 150 \\
\hline Time $j$ (min) (Push cart) & 65 & 70 & 67 & 70 & 65 & 74 \\
\hline Waste collected (kgs) & 116 & 192 & 210 & 240 & 160 & 110 \\
\hline
\end{tabular}

The study area is Jayanagar $7^{\text {th }}$ block. Collection points $(i)$ are situated near 30th cross, Jayanagar $7^{\text {th }}$ block, where the compactor truck is stationed. Data is primary, collected from pourakarmikas. Pushcarts as well as small auto-tippers as well as small tempos are used for collecting from households as well as transporting it to compactor location. On an average, it takes about 2 hours to collect from 80 houses. Each household generates about $2 \mathrm{~kg}$ of waste (4 members/ household) and thus, about 160kgs. The situation is studied in a small area consisting about 800 households spread in close geographical proximity. This is because if the area is wide spread, we cannot consider the use of pushcarts, as distance traveled will be large. All wastes collected in taken to compactor lorry stationed at 30th cross, Jayanagar $7^{\text {th }}$ Block. See Table 2 for the details.

- Capacity of push cart is $100 \mathrm{~kg}$

- Capacity of larger truck is $800 \mathrm{~kg}$

Using LINGO 17.0, we get the following profile of large and small trucks.

Table 3: Profile of Trucks

\begin{tabular}{|c|c|c|c|c|c|c|}
\hline Variables & $\mathrm{X}_{1}, \mathrm{Y}_{1}$ & $\mathrm{X}_{2}, \mathrm{Y}_{2}$ & $\mathrm{X}_{3}, \mathrm{Y}_{3}$ & $\mathrm{X}_{4}, \mathrm{Y}_{4}$ & $\mathrm{X}_{5}, \mathrm{Y}_{5}$ & $\mathrm{X}_{6}, \mathrm{Y}_{6}$ \\
\hline Values & 0,2 & 1,0 & 1,0 & 1,0 & 1,0 & 0,2 \\
\hline
\end{tabular}

Thus, we get the solution that 4 trips of large and 4 trips of small trucks are needed for optimality. To get the number of trucks and allotment of trucks to different trips, we use Bin packing problem, formulated below.

\subsection{Bin Packing Formulation for the above profile ob- tained from milk run}

Using milk run, we get the optimum type and number of trips so that the total cost of Milk Runs is reduced.

We now use bin-packing problem to find the number of trucks required, in other words, the number of trips has to be 'packed' into 'trucks'. Let us assume that each truck is available for 6 hours every day. The bin-packing problem is solved separately for the large and small trucks.

The decision variables of the bin- packing problem are

- $\quad$ The number of trucks required, given by index $i$

- The allocation of trips to trucks, given by $\mathrm{p}_{i j}$

The objective function is given by

Minimize $\mathrm{Z}=\sum \mathrm{k}_{\mathrm{i}}, i=1$ to $n$.

Subject to:

$\sum \mathrm{w}_{\mathrm{j}} \mathrm{p}_{\mathrm{ij}} \leq 360 \mathrm{k}_{\mathrm{i}}, i=1$ to $n$.

$\sum \mathrm{p}_{\mathrm{ij}}=1 \forall j=1,2, \ldots, \mathrm{n}$;

where $\mathrm{k}_{\mathrm{i}}=1$ if the $i^{\text {th }}$ truck is used and 0 otherwise,

$\mathrm{p}_{\mathrm{ij}}=1$ if the $j^{\text {th }}$ trip is assigned to the $i^{\text {th }}$ truck and 0 otherwise, and $\mathrm{n}=\sum \mathrm{x}_{\mathrm{i}}=\sum \mathrm{y}_{\mathrm{i}}, i=1$ to $n$.

where $\mathrm{w}_{\mathrm{j}}$ is the time duration of the $j^{\text {th }}$ trip.

Using the Bin-packing problem separately for large and small trucks, we get the following solution.

Small trucks- 4 trips are needed (solution of Milk run) and 2 trucks are required (according to Bin-packing), assuming that small trucks are available for $3 \mathrm{hrs}$ in a day.

Table 4: Small Truck Assignment

\begin{tabular}{|c|c|c|}
\hline Truck & 3 & 4 \\
\hline \multirow{2}{*}{ Assigned to trip number } & 1,2 & 3,4 \\
& (collection point A) & (collection point F) \\
\hline
\end{tabular}

Large trucks- 4 trips are needed (solution of Milk run) and 4 trucks are required (according to Bin-packing), assuming that large trucks are available for 2.5 hours each day.

\begin{tabular}{|c|c|c|c|c|}
\hline Truck & 1 & 2 & 3 & 4 \\
\hline Assigned to trip number & 2 & 3 & 4 & 1 \\
\hline
\end{tabular}

\section{Results and Discussions}

Using Milk run, it is evident that the cost will reduce, as we require less number of trucks. Instead of 6 trucks to transport waste from 6 locations, we use only 4 trucks, in combination with pushcarts to transport waste.

These optimization techniques will benefit waste management agencies, as the objective is time minimization, which will result 
in minimization of costs. The major problem faced by civic agencies is budget and hence the application of optimization techniques will help in attaining this objective. Instead of deploying multiple vehicles, there is less number of vehicles involved and as round trip timings are taken, the time for waste collection can be planned. Milk run is heavily dependent on co-operation between various agencies and thus will result in more interaction between different civic agencies.

In milk run optimization, we construct the number of trips, which different waste collection vehicles have to make, for optimizing costs. These costs of trips are in terms of time taken. Thus, this can be considered as a time minimization problem. The round trips of various types of vehicles, including collection and transporting to a sink, are measured in terms of time units. After getting the profile of number of trips required, we can use bin-packing problem to assign different types of vehicles to various waste collection points.

In this research, primary data obtained by pourakarmikas of Bangalore city have been used, along with secondary data provided by the local ward office. The data from pourakarmikas are regarding the round trip and the ward office gave information regarding the number of trucks. While the milk run problem gives the number of trips, the extension of the problem using bin-packing formulation gives the number of vehicles of different types as well as allocation of trucks to trips. These can help civic agencies to plan vehicle scheduling, avoiding unnecessary trips and thus saving on cost.

\section{References}

[1] Baudin M (2005), Lean logistics: the nuts and bolts of delivering materials and goods, CRC Press.

[2] Brar GS \& Saini G (2011), Milk run logistics: literature review and directions, In Proceedings of the world congress on engineering, 1, 6-8.

[3] Chen J \& Shuaiying (2009), A Cost Optimization Model Based on the Milk Run System for the Three-Level Supply Chain, J. WUT (Information and Management Engineering) 31, 838-842.

[4] Chopra S \& Meindl P (2014), Transportation in a Supply Chain, Supply Chain Management: Strategy, Planning, and Operation, 6 ed., Pearson, 412-444.

[5] Du T, Wang FK \& Lu P (2007), A real-time vehicle-dispatching system for consolidating milk runs, Transportation Research Part E: Logistics and Transportation Review 43, 5, 565-577.

[6] http://www.mhlnews.com/global-supply-chain/jaguar-paneuropean-inbound-contract-dhl (Aug 05, 2009).

[7] Meyer A (2017), Milk run design: Definitions, concepts and solution approaches 88 , KIT Scientific Publishing.

[8] Sadjadi SJ, Jafari M \& Amini T (2009), A new mathematical modeling and a genetic algorithm search for milk run problem (an auto industry supply chain case study), International Journal of Advanced Manufacturing Technology 44, 1-2, 194.

[9] Vig MG, Bolia N \& Sundararaman G (2013), Optimization of 'Milk Run'of JCB India Ltd.(Ballabhgarh Plant), Journal of Traffic and Logistics Engineering 1, 2, 137-140.

[10] Womack JP, Jones DT \& Roos D (1990), The Machine That Changed the World: The Story of Lean Production: How Japan's Secret Weapon in the Global Auto Wars Will Revolutionize Western Industry, Rawson Associates, New York. 